Fecha de recepción: abril 2020

Fecha de aceptación: mayo 2020

Versión final: junio 2020

\section{Steampunk: análisis del carácter crítico de sus producciones objetuales}

Martín Tisera ${ }^{(1)}$

Resumen: Abordamos en este trabajo la genealogía de este concepto que busca contextualizar las obras que transcurren en el futuro imaginado por los escritores de ciencia ficción Julio Verne y H. G. Wells, a finales del siglo XIX. Convertido en una subcultura en la década de 1990, el Steampunk recupera para su estética elementos de la máquina victoriana. Este procedimiento puede observarse hoy, y cada vez con mayor frecuencia, en los diferentes ámbitos de la producción visual. El análisis se propone analizar los modos en que algunos de los objetos producidos por esta subcultura adquieren una dimensión crítica.

Palabras clave: Steampunk - Ciencia ficción - Crítica.

[Resúmenes en inglés y portugués en la página 45]

(1) Magíster por la Facultad de Arquitectura, Diseño y Urbanismo de la Universidad de Buenos Aires y egresado de la Maestría en Diseño Comunicacional (DICOM).

\title{
Introducción
}

Si bien el Steampunk nace a finales de la década de 1980 como un género literario, podría decirse que este es sólo su espacio inaugural. Esto es así porque a partir de su establecimiento, comienza a expandir sus límites hasta tomar con sus singulares características los distintos ámbitos de la producción visual. En efecto, el Steampunk se constituye como una subcultura en los años ' 90 . Desde entonces, su estética, vinculada con una avanzada tecnología futura hecha con elementos propios del siglo XIX, ha rubricado el carácter de películas, series, cómics, esculturas, eventos, entre muchas otras manifestaciones.

Tal cantidad y variedad de producciones requerirá de este análisis, en primer lugar, una clara distinción entre dos accesos posibles al Steampunk. El primero, es el que se halla ligado al encanto superficial inspirado por una época ficticia. Luego está el ingreso que se encuentra comprometido con el aspecto crítico que, por ser un subgénero de la cienciaficción (circunstancia que se subrrayará), esta subcultura lleva consigo.

Una discriminación así será necesaria porque es justamente este último posicionamiento lo que interesa a la presente indagación. Se revisará entonces, las ideas de quienes defien- 
den esta alternativa, observando especialmente a Richard Nagy y a Jake von Slatt pues, además de expresarse sobre este tema, fueron pioneros en la elaboración de objetos. Para ellos, los materiales y lógicas de construcción que hacen a la personalidad visual del Steampunk, no funcionan como ingenuas invenciones retrofuturistas, sino que dan cuenta de un consciente sentido crítico. Se trata, más específicamente, de operaciones que otorgan a un dispositivo actual (como la computadora), la apariencia de un objeto perteneciente a la época victoriana.

Es cierto que esta clase de procedimientos puede detectarse en distintos aparatos, sin embargo, adquiere mayor sentido cuando actúa sobre productos de tecnología informática de última generación. Estos son objetos que, con mayor fuerza que otros, se hallan desligados de todo atributo ubicado por fuera de la utilidad y de la eficiencia, además de tener una fuerte presencia en la vida cotidiana de sus propietarios. Cabe aclarar que este tipo de prácticas no niega el avance tecnológico, de ahí que las intervenciones afecten sólo la fisonomía del artefacto y dejen intactas sus prestaciones.

Se verá cómo estos objetos, convertidos en únicos, proponen un cambio en el tipo de relación que se tenía con sus versiones originales. En este sentido, la defensa de un valor afectivo inherente a la materialidad y a la factura manual, funciona como un cuestionamiento hacia el principal modo de consumo actual basado en el veloz deshecho y recambio de productos iguales.

Aquí aportarán las ideas de Ezio Manzini, consciente de esta dinámica de reemplazo acelerado y de la importancia de recuperar la realidad material (fuertemente disminuida) de los objetos. Luego, Donald Norman contribuirá con una dimensión psicológica al revelar los modos en que la apariencia de un producto influye en el ánimo de su operador, alterando, muchas veces, los resultados. La forma en la que se presentan los aparatos de la actual tecnología informática, también será abordada por Byung-Chul Han, quien verá en éstos objetos pulidos una "perfección" que anula la distancia contemplativa y se convierte en un área de consumo total.

Finalmente, se estudiará la manera en que, para su propósito crítico, adquiere relevancia la cita expresa que el Steampunk hace al siglo XIX. En ese tiempo, ésta subcultura ve un momento clave en la definición del rumbo que ha tomado la tecnología y la relación que los hombres tienen con ella. Desde la imaginación, por supuesto, el Steampunk reescribe el pasado para ensayar un nuevo futuro que cuestiona el presente.

\section{El origen del pensamiento crítico Steampunk}

El Steampunk es conocido habitualmente por sus fantasías de estética retrofuturista, es decir: por mostrar un futuro hecho con elementos del pasado. Ahora bien, fuera de estas construcciones, es menos difundida su producción de objetos de uso cotidiano y su intervención sobre dispositivos actuales de tecnología informática. Sin embargo, éstos últimos revisten una gran importancia para este análisis, pues cuestionan varios aspectos de los productos regulares y de las prácticas de consumo de la sociedad presente. Sin embargo, revisar dicha posición crítica impone comenzar por los orígenes de esta subcultura. 
El escritor Kevin Wayne Jeter acuñó la palabra Steampunk en 1987. Lo hizo en una carta publicada en el número cuatro de Locus: The Magazine of The Science Fiction \& Fantasy Field. El término pretendía englobar las nuevas obras literarias contextualizadas en el futuro imaginado por Jules Verne y Herbert George Wells a finales del siglo XIX. Cabe añadir que con steam (vapor) se hace referencia a un tipo de tecnología propio de la época victoriana. Pero Jeter no sólo definió el nombre para aquella clase de historias. Su novela Morlock Night (1979) - una continuación de The Time Machine, escrita por Wells en 1895es considerada como el primer relato genuino del estilo. Sin embargo, Infernal Devices: A Mad Victorian Fantasy (1987) es reconocida como la primera obra desarrollada intencionalmente bajo las características que definieron a esta flamante literatura. Se trata, principalmente, de un anacronismo que resulta de articular las posibilidades de una imaginada tecnología futura con elementos de la máquina decimonónica. Jeter se ubica además entre los precursores en el trabajo sobre una de las especulaciones más recurrentes de este género, vinculada con los cambios sociales que derivan de una intervención tecnológica como la computadora.

No obstante lo dicho, Cory Gross (2006) advierte la importancia, para comprender verdaderamente al Steampunk y diferenciarlo de otros casos en apariencia similares, de remitirse a sus orígenes en la ciencia-ficción. Este autor propone incluso analizar las bases de este último género literario, allí donde los escritores comenzaban a delinear sus principales características.

En este sentido, Juan José Millás (1982) ve a la ciencia-ficción como “un fenómeno literario y social relativamente moderno" (p. 12) que no debería confundirse con ciertos sucesos históricos inexplicables que sólo podrían significar una fuente para sus temas. Ejemplo de esto son los descubrimientos iconográficos que fueron interpretados, en más de una ocasión, como indicios de un desarrollo tecnológico muy adelantado en civilizaciones antiguas como la Maya. Conjeturas ulteriores llevaron a considerar que tales avances fueron los responsables de que esas culturas perecieran.

Aquí es donde ve parte de su génesis un postulado clave para muchas obras de cienciaficción: "la evolución tecnológica conduce inevitablemente a la autodestrucción" (Millás, 1982, p. 12). Así pues, este género utópico (entendiendo por utopía la inmersión en una situación inexistente por futura), se muestra pesimista con respecto al porvenir señalado por las alternativas tecno-científicas en vigencia.

Asimismo, aquella suerte de máxima, sustrato de gran cantidad de producciones, se alimenta de hechos palpables y dignos de considerarse. En efecto, Louis Pauwels y Jacques Bergier (1975), recuerdan a un Wells desengañado hacia el final de su vida en 1946. Testigo de nuevos inventos destinados a la destrucción masiva, su fe en el progreso había trocado en desesperanza. El rumbo tomado por la ciencia amenazaba con destruir el planeta.

Sucede que Verne y Wells vivieron para atestiguar -y tomar como inspiración- el doble sentido que adquirieron los avances tecnológicos vinculados con sucesos desafortunados. Murray Bookchin (1999) no pasa por alto la paradoja que revisten las invenciones técnicas y apunta que el entusiasmo que se siente por ellas se ve anulado ante la constatación de sus efectos: 
El hecho de que los instrumentos que nuestras mentes idearon y nuestras manos crearon puedan volverse fácilmente en nuestra contra nos deja perplejos, ya que lo que se pone en juego es nuestro bienestar, y más aún, nuestra supervivencia misma como especie (p. 333).

Sin embargo, y refiriéndose a las máquinas, no resulta extraño para Lewis Mumford (2006/1934) que el absolutismo y la guerra fueran "el estímulo de la inventiva, cuando no su inmediato sustento práctico" (p. 475). Éste autor considera que las máquinas sufrieron en sus inicios, fuertes condicionamientos que no contemplaron tipo alguno de bienestar social. Muy por el contrario, se priorizó el lucro privado y el provecho de las clases dominantes. Por lo tanto, Mumford (2006) descree de que, sin los intereses del capitalismo y la guerra, las máquinas pudieran haberse desarrollado al ritmo con el que lo hicieron.

Importa mencionar que es esta ambigüedad -interpretada por Verne y Wells- la que, en opinión de Jeff VanderMeer (2011), no sólo influyó, sino que estimuló la creación de la cultura Steampunk a finales del siglo XX. Subrayar entonces esta relación hereditaria con la ciencia-ficción -circunstancia descuidada y hasta inadvertida en numerosas fuentesresulta significativo, dado que de allí toma el Steampunk su carácter crítico enfocado en el rumbo tomado por el desarrollo tecnológico.

\section{Compromiso crítico o despreocupado entretenimiento}

No obstante lo dicho sobre los cuestionamientos que el Steampunk sigue de la cienciaficción, existe además otro modo de ingresar a esta subcultura. Éste responde, se podría decir, a cierta fascinación por la novedad de una estética retrofuturista que, en su expansión, ha ido solapando aquel componente originario. Pasar enseguida a una distinción entre ambos modos de experimentar el Steampunk, permitirá dejar de lado prontamente una visión que, aun siendo la más difundida, no corresponde al interés de este trabajo, puesto en la posición que deviene en la construcción de objetos críticos.

Una escisión clara en este sentido, es la que aporta Gross (2006), quien divide al Steampunk en dos grupos basándose en la diferencia entre Verne y Wells. Según este criterio, el Steampunk Nostálgico, que sigue la línea del primer escritor, está centrado en la belleza estética de la época victoriana, en la exploración de nuevos mundos y en la reconstrucción de este período como debería haber sido. Esta visión soslaya todos los componentes negativos de aquel momento histórico, entre los que pueden mencionarse la pobreza, la explotación, la polución, la corrupción y la decadencia resultado del capitalismo y el imperialismo. Luego, se encuentra el Steampunk Melancólico, donde se resalta todo lo que la categoría anterior tiende a ignorar. Este segundo grupo cuestiona indirectamente a la sociedad actual a través de lo que observa en el período victoriano.

Una dicotomía semejante a la planteada por Gross (2006), es la que advierte VanderMeer (2011) cuando señala que se puede optar entre dos alternativas dentro del Steampunk. Este punto de vista sugiere que es posible comprometerse con reflexiones similares a las 
encaradas por Verne y Wells, pero en la actualidad; o tomar de estos escritores únicamente la configuración victoriana y el encanto naif de unas raras invenciones.

De todos modos, y más allá de otros abordajes posibles, parece insoslayable atender a la declaración de principios que revela la palabra "punk". Para Rebecca Onion (1998), el agregado de ese término se desprende de entender que el Steampunk es una subcultura a la que sus participantes "ven -leyendo, construyendo y escribiendo sobre tecnología a vapor-, como una práctica contracultural altamente liberadora" (p. 139).

Aun así, The SteamPunk Magazine -si no la única, la primera revista especializada en esta subcultura- advierte un debilitamiento del componente crítico, en verdad distintivo de la posición Steampunk. Y tal es la importancia que le ha dado esta publicación a aquel deterioro, que salvarlo se ha convertido en su finalidad. De aquí que en su eslogan se lea: "Devolviéndole el Punk al Steampunk".

Por esta razón, la revista incluye entre los autores de sus artículos al grupo The Catastrophone Orchestra and Arts Collective ${ }^{1}$ (en adelante CO\&AC) (2006), quien hace notar que mucho de lo que hoy se hace pasar por Steampunk, contradice en realidad al punk entendido como "la mecha utilizada para encender los cañones" (p. 5). No menos importante resulta la interpretación que del Steampunk hace el mencionado grupo. En ella se lo ve como una "crítica no ludista a la tecnología" (p. 4). No se trata entonces, en modo alguno, de aquellas manifestaciones en las que el Steampunk es entendido como una especie de nostalgia superficial en la que se añora, de una manera cándida, ciertos objetos o circunstancias de la época victoriana (salones de té, mapas coloniales, tonos sepia, etc.). Esto es considerado por CO\&AC (2006), como una mera artificialidad que se encuentra más cerca de las producciones de Disney, que de "una vibrante y viable filosofía o cultura" (p. 4). VanderMeer (2011) contribuye a esta idea al considerar que algunas áreas en las que el Steampunk se ha manifestado pueden verse impregnadas de cierta ingenuidad. Sin embargo, lo que esta subcultura ha heredado realmente, son las predicciones nefastas que Verne y Wells formularon con respecto a la tecnología aplicada a la guerra, además de otros temas como la sustentabilidad. Por otra parte, y todavía en opinión de VanderMeer (2011), existe una recurrencia a la capacidad imaginativa de Verne y a la utilización del "enfoque sociológico de Wells" (p. 44), procedimiento que tiene por objetivo modificar el porvenir. De este modo, el Steampunk "reescribe los planos, reinventa la tecnología a vapor y revive el romance científico para crear un mundo consciente de sí mismo, que es hermoso y al mismo tiempo nostálgico, pero que también reconoce la distopía ${ }^{2 ”}$ (p. 44).

Es que el acto crítico está por cierto en el "regreso". VanderMeer (2011) observa que, si bien algunos procedimientos son prácticamente los mismos, la diferencia con respecto a la ciencia-ficción es que el Steampunk cambia el énfasis y el contexto, muchas veces, de una manera radical. En efecto, el Steampunk "vuelve" a un momento histórico en el que aún podían tomarse otro tipo de decisiones, diferente del que dio cumplimiento a las aciagas predicciones de su género padre. En ese salto hacia atrás, recupera el entusiasmo del positivismo científico y propone, desde la imaginación, la sustitución de un pasado por otro. Con esto ensaya la visión de un futuro que se desprendería de tal reemplazo.

Richard Nagy (de quién se hablará en profundidad más adelante), explica en una entrevista para VanderMeer (2011) su visión del "regreso" que propone el Steampunk a los años de la Revolución Industrial: "Hemos ansiado desesperadamente y por tanto tiempo 
el futuro que no sabemos qué hacer con él ahora que está aquí. No es de extrañar, pues, que miremos al pasado, probando y buscando explicaciones y metáforas que nos ayuden a arreglarlo" (p. 107).

Una vez más, el Steampunk "vuelve" a la segunda mitad del siglo XIX. Pero no lo hace padeciendo una visión infantil o sesgada sobre ese pasado que a su modo recupera. No desconoce los aspectos desfavorables de ese momento histórico. El Steampunk es en realidad, una suerte de retroceso para un avance en otra dirección. Es la vuelta a un punto de inflexión, un lugar clave en el tiempo donde se considera importante haber tomado otras decisiones. Según VanderMeer (2011), el Steampunk pretende desde sus singularidades,

Reparar el daño causado por la industrialización. No se trata simplemente de un intento por limpiar el clasismo, el racismo y la explotación que conformaron parcialmente la era victoriana, es en cambio un impulso para recuperar el pasado muerto, de un modo positivo y afirmativo (p. 44).

En términos generales, según Tim Wetherell (2012), el Steampunk resulta en "un pasado que nunca fue, un futuro que nunca sucedió; tal vez lo mejor de ambos mundos".

\section{Los "hacedores" del Steampunk}

Desde su aparición a finales de los años ' 80 , el Steampunk ha evolucionado notablemente. Superó su ámbito de origen en la literatura y se volcó sobre nuevas y diversas áreas. La magnitud que alcanzó este desarrollo condujo a VanderMeer (2011) a plantear que la mayoría de las personas que hoy día se consideran steampunks no ha leído la narrativa de este género. El acceso se produjo mediante otros caminos, como la historia, los medios visuales y la moda, verdaderos causantes de una subcultura en la década de 1990. Es que el Steampunk impregnó con su estética no sólo un buen número de películas y cómics, sino también otro tipo de espacios vinculados con el arte. En este sentido, el Steampunk es para VanderMeer (2011) ampliamente inclusivo, e incentiva "a ser aplicado en diversas propuestas, tanto fantasiosas como prácticas" (p. 11).

Onion (1998) acentúa en su análisis sobre este tema, la existencia de una cultura Steampunk que se encuentra definida más por los objetos que producen sus integrantes que por las expresiones literarias que le dieron origen. La autora considera que no se busca recrear una tecnología específica de la época victoriana tanto como sostener un valor afectivo vinculado al mundo material de esa época. Más específicamente, ese repertorio se halla compuesto por "el latón, el cobre, la madera, el cuero, y elementos como engranajes, resortes, ruedas, piñones, etcétera” (p. 138-139).

De todas formas, VanderMeer (2011) observa que, más allá de una estética compartida vinculada con los materiales recién mencionados por Onion (1998), no resulta fácil clasificar a los "creadores" Steampunk. El autor señala que algunos de ellos se autodefinen como artistas; mientras que otros, como makers. La diferencia estriba en que los primeros, construyen objetos como instalaciones y esculturas conduciéndose según los códigos pro- 
pios del campo artístico (procesos y terminología). Los segundos, en cambio, recuperan viejos dispositivos, o bien se dedican a modificar aquellos que fueron desarrollados en base a una tecnología actual. De todos modos, el autor señala que los límites son imprecisos, y que la influencia entre ambos sectores resulta frecuente y, al mismo tiempo, valiosa. Conviene agregar que, según Bruce Sterling (2011), el noventa por ciento de las personas que dice formar parte del Steampunk, se contenta en éste experimentándolo como un "juego de disfraces y alegre entretenimiento subcultural" (p. 12). Es por esta razón que el autor invita a los jóvenes a involucrarse en ese diez por ciento restante, constituido por quienes hacen realmente el Steampunk. Exhorta además a los interesados a adherir al aspecto "punk" vinculado al DIY (do it yourself), lo que significa un combate contra las grandes compañías. Y hay que decir al respecto, aunque sea entre paréntesis, que con este tipo de práctica los steampunks pretenden recuperar la polivalencia de una figura encarnada en el inventor decimonónico. Se trata, a grandes rasgos, de un hombre que lograba conjugar en sus invenciones, una amplia diversidad de saberes. Esta clase de trabajo interdisciplinario pretende desmontar lo que CO\&AC (2006) llama "las siempre crecientes jaulas de la especialización" (p. 4).

Aún más, VanderMeer (2011) advierte que los steampunks marcan el nacimiento de su cultura en la insatisfacción con los productos monolíticos fabricados en serie de la tecnología contemporánea. Se trata de un desacuerdo con el modo masivo de producción que simplificó el diseño de los productos, quitándoles su individualidad en favor de una mayor productividad.

Es así que Jake von Slatt (2009), maker destacado y creador del manifiesto Steampunk, muestra su disconformidad hacia los productos fabricados en masa que resultan para él idénticos y descartables. Slatt (2009) pone por caso "el progreso recién salido de un molde de plástico que venden Ikea o Microsoft”. En acuerdo con esta posición, Calamity (2007), miembro fundador de CO\&AC, piensa que "cuando todo es igual, nada tiene valor", y agrega presentando un ejemplo: "El iPod, para nosotros, es muy impersonal y desechable". En contraposición a esta clase de objetos, deduce Marian Kuemmerlein (2007), los generados por el Steampunk nunca se pondrán realmente de moda, ya que no es posible producirlos en serie. Slatt (2011) señala todavía, que "los steampunks evitan el consumismo de la cultura popular” (p. 218), y más adelante agrega:

Los steampunks quieren comprar algo una vez y luego pasárselo a sus hijos. Aún mejor, queremos hacer algo una vez, algo que usaremos todos los días por el resto de nuestras vidas. Algo que nos recuerde siempre que lo utilicemos que tenemos destreza y habilidad. Algo que nadie más en el mundo tenga (p. 218).

En este sentido, Donald Norman (2005) entiende los objetos de factura propia como aquellos más personales y capaces de generar recuerdos gratos. Siguiendo este criterio, el autor observa la necesidad de un tiempo prolongado de interacción con los objetos para experimentar hacia ellos emociones firmes, asociaciones íntimas de relevancia y evocaciones. La utilidad juega en este caso, un rol menor.

Richard Nagy (2011), otro maker de renombre y fundador del proyecto Datamancer, considera que el Steampunk puede funcionar asimismo, como "una defensa contra el consu- 
mismo desenfrenado, al reconectar a las personas con un arte culturalmente obsoleto de fabricación y con el ingenio" (p. 106). En tal procedimiento interviene además, la visión del propio trabajo "no sólo como la construcción de productos, sino de herencias" (Nagy, 2012).

Sobre ésto, Manzini (1996) reconoce la existencia de objetos cuya duración es contemplada en su elaboración, adquisición y uso. Esto se debe a la prevalencia de una necesidad cultural inclinada hacia las cosas que, por haber preexistido, funcionan como testigos de un pasado. Se trata de objetos que sí resultan capaces, no sólo de guardar memoria, sino de ingresar en la afectividad de las personas. Al constituirse como referencias temporales, se pretende que sean ellos los que perduren a una indefinida sucesión de usuarios. Por ello Slatt (2011) advierte el interés de muchas personas en una tecnología antigua "en la creencia de que sólo las máquinas de una era pasada tenían la durabilidad para sobrevivir a sus propietarios" (p. 216). De aquí la gran importancia que Norman (2005) le atribuye al recuerdo por su facultad de "convocar" personas, vivencias, logros, y de robustecer la imagen que se tiene de uno mismo.

\section{Un cambio en la relación artefacto-usuario}

Se ha dicho que no es fortuito el momento histórico que el Steampunk pretende retomar. De las problemáticas ya planteadas, cuyos orígenes son vistos en aquel tiempo, conviene profundizar ahora sobre un aspecto adelantado en el apartado anterior. Se trata de la relación entre los artefactos y sus propietarios.

Según Ezio Manzini (1996), una creciente disminución en los tiempos de producción y consumo ha cambiado a los artefactos y a las relaciones que con ellos se tienen. Éstas se hallan así, más ligadas al servicio que a una determinada entidad matérica. En el constante reemplazo de productos iguales, la única continuidad posible es la de la prestación. Esto sucede porque no existe en tales artefactos de rápida caducidad, una permanencia de su realidad física.

No huelga añadir que para Mumford (2010/1967), la civilización premecanizada distaba mucho de "sacrificar la invención estética o la corrección funcional para duplicar la producción, o incluso para acelerar el proceso productivo" (pp. 413-414). Es cierto que priorizar la calidad de los artículos ralentizó la producción y mantuvo un número reducido de compradores, pero también es verdad que, como contrapeso, se contribuía disminuyendo "el ritmo de la obsolescencia y eliminando una gran fuente de derroche" (pp. 413-414). Pero el problema radica para el autor, en la cultura actual:

... centrada en el culto de las fuentes de energía, adoradora de las máquinas, respetuosa de lo uniforme, de lo producido y consumido en masa, desdeñosa de la individualidad, la variedad y la elección, salvo en lo que respecta a la conformidad estricta a las demandas de la megamáquina (pp. 414-415). 
Así pues, una de las diferentes formas en que el hombre se relaciona con su medio material tiene que ver, para Abraham Moles (1990), con la aceleración consumidora. Según este criterio, el objeto es visto como:

Un momento transitorio de la existencia de una multiplicidad, tomada en un momento determinado de su vida, que se extiende entre la fábrica y el tacho de la basura, así como la vida del hombre se extiende entre la cuna y la tumba (p. 22).

Es a través del acto de consumir, "la nueva alegría masiva" (p. 25), que el hombre "hace desfilar a lo largo de la vida cotidiana un flujo siempre acelerado de objetos (...) condenados necesariamente a lo transitorio, a lo provisorio" (p. 25). A diferencia de lo que sucedía en el siglo XIX, y por su nueva condición de efímero -continúa el autor-, el objeto se ha convertido ahora en producto.

Lo que sucede es que, según Calamity (2007), es en la época victoriana, y no en un posible futuro, donde se encuentra una clase de relación entre el hombre y la tecnología "más honesta de lo que es ahora". Ya VanderMeer (2011) observa que el Steampunk pretende recuperar un tipo de inventiva hallada en las máquinas del siglo XIX. Siguiendo las ideas de este autor adelantadas más arriba, muchos steampunks consideran que la subcultura a la cual pertenecen surge, en parte, como una insatisfacción con respecto al diseño actual de los productos informáticos, entendido como "desalmado, conformista, y carente de rasgos distintivos" (p. 98). Su criterio de uniones prácticamente indetectables, hace lucir a los artefactos por demás antisépticos [sic]. Se suma a esto último, el juicio de Nagy sobre tales dispositivos, vistos como algo "demasiado aburrido y utilitario" (Nagy, 2011, p. 107). Y por cierto que es este parecer lo que impulsó la construcción de los objetos Datamancer. Una dimensión más profunda sobre este asunto es aportada por el filósofo coreanoalemán Byung-Chul Han (2015), quien observa que "lo pulido, pulcro, liso e impecable es la seña de identidad de la época actual" (p. 11-13). De este modo, el autor pone en común el iPhone (pero también el smartphone), las esculturas de Jeff Koons y la depilación brasileña. Han (2015) explica a renglón seguido las razones del atractivo que ejerce hoy lo pulido:

¿Por qué lo pulido nos resulta hoy hermoso? Más allá de su efecto estético, refleja un imperativo social general: encarna la actual sociedad positiva. Lo pulido e impecable no daña. Tampoco ofrece ninguna resistencia. Sonsaca los "me gusta". El objeto pulido anula lo que tiene de algo puesto enfrente. Toda negatividad resulta eliminada (p. 11-13).

Este autor insiste, refiriéndose especialmente a los teléfonos celulares, que lo pulido (seamless para VanderMeer) no es privativo del aspecto, pues el tipo de comunicación efectuada mediante estos dispositivos es asimismo "pulimentada y satinada" (Han, 2015, p. 13). Toda cosa ajena a lo positivo, a la condescendencia o la satisfacción es tachada de impedimento para el intercambio acelerado y, por lo tanto, evitada o excluida. Por otro 
lado, lo pulido "activa el imperativo táctil" (p. 13) disolviendo la distancia contemplativa que todo juicio estético requiere. Al mismo tiempo, la ausencia de lejanía anula lo místico: "Al contrario que el sentido de la vista, el tacto es incapaz de asombrarse. Por eso la pulida pantalla táctil, o touchscreen, es un lugar de desmitificación y de consumo total" (p. 15). Así es dado considerar que las modificaciones propuestas por los makers reubican la importancia de ciertos atributos esperables en la clase de objetos que intervienen. De este modo, por ejemplo, valores como la portabilidad o la velocidad de acceso a las prestaciones que ofrece una computadora, se ven alterados en beneficio de una mayor durabilidad, pero además, de una honda personalización del objeto. Casos que responden a esto último son: The Victorian all in one PC, la computadora personal realizada por Jake von Slatt (Figura 1); The Victorian Steampunk Laptop (Figura 2) y The Telegraph Mouse (Figura 3), hechos por Datamancer.

Se trata a su vez, reiterando lo ya expuesto en el manifiesto de Slatt (2011), de conseguir una mayor apropiación de los artefactos que pertenecen al uso cotidiano. En ellos se espera que participe todavía, dentro de lo posible, la mano trabajadora del propio usuario. Esto contribuye, como se vio, a fortalecer una conexión afectiva con los objetos, relacionada al logro, a la exclusividad y a la evocación del pasado.

A propósito de ésto, en su reflexión sobre las temporalidades de los objetos hechos por el hombre, Manzini (1996) señala que "la materia es el sustrato estable de nuestras experiencias" (p. 55) en contraposición a la dinámica veloz de las ideas. En efecto, a través del extendido uso que el ser humano hizo de un limitado repertorio de materiales, se ha conseguido una "acumulación de memoria subjetiva y colectiva" (p. 56), lo que derivó en una "semántica de los materiales y de las formas" (p. 56). De este modo, con el establecimiento de una relación entre cualidades físicas y culturales, los diferentes materiales fueron hallando su identidad. Los objetos, por consiguiente, "que surgen de la dialéctica entre las ideas y la materia” (p. 56), se ven impregnados de una serie de características que le pertenecen, ya como esenciales, a los materiales con los que fueron construidos.

Pero eso no es todo. Manzini (1996) considera que, en relación con el consumo, han aparecido al ingresar la década de 1990, algunas contratendencias que pusieron de relieve el requerimiento de "productos más 'duraderos' y 'profundos"' (p. 21). Estas contratendencias (se recuerda el nacimiento del Steampunk como subcultura en el período que indica el autor), van en sentido contrario a las propuestas de la década anterior, y representan "un área de la demanda social con la que es posible actuar recíprocamente dando más visibilidad y coherencia a sus exigencias" (p. 21).

Por otro lado, según las observaciones realizadas por Norman (2005), quien repara en la fuerza emocional que diversos diseños pueden generar, las personas se ven inclinadas hacia las configuraciones formales de los productos y hacia las impresiones vivenciadas durante su puesta en uso. De este modo, la prestación específica y el buen funcionamiento se convierten en atributos que, de alguna manera, quedan relegados a un orden inferior. Resulta que existe un sólido factor emocional vinculado con el diseño y utilización de los productos. Este elemento tiene para el autor un peso mucho mayor, respecto al éxito o fracaso de un determinado producto, que aquellos otros aspectos que responden a su practicidad.

Norman (2005), con el respaldo de su investigación, afirma que los objetos más atractivos estéticamente, teniendo en cuenta los sentimientos que evocan, permiten a sus usuarios 


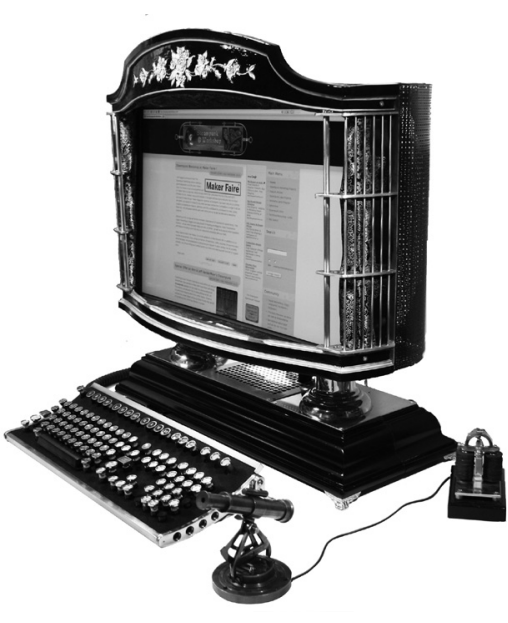

Figura 1.

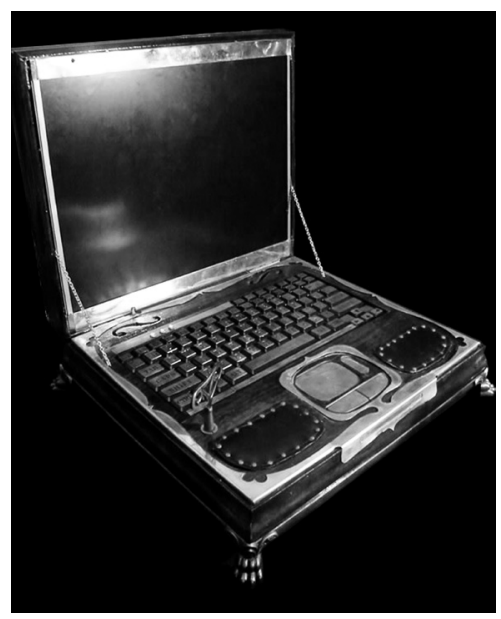

Figura 2.

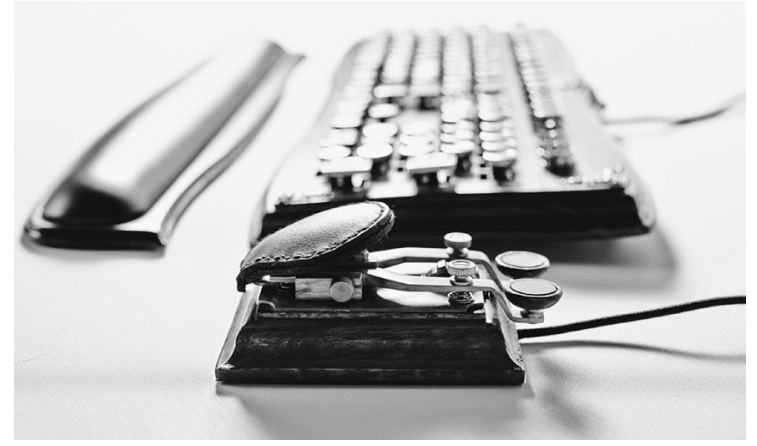

Figura 3.

un mejor desempeño, incluso sin ser, estos objetos, los más eficientes. Aún más, los productos y sistemas que elevan el estado anímico se manejan de un modo más sencillo y obtienen óptimos resultados. Distinto sucede con los objetos entendidos como usables, que no implican una experiencia placentera. Resulta de importancia, entonces, que la manera en que se ven los objetos utilizados habitualmente logre influir de un modo positivo en las emociones, pues éstas son capaces de modificar la manera en que funciona el sistema cognitivo. De esta forma, los problemas a los que se enfrentan las personas pueden ser resueltos de un modo diferente a través de un pensamiento más creativo. 
Por último, y para abonar la idea de un cambio en la relación que las personas tienen con sus artefactos, Manzini (1996) propone despojar ése término de su connotación negativa. En efecto, frente a la visión de un ambiente futuro inevitablemente artificial, el autor sugiere pasar de la acepción de "artefacto" que sugiere algo falso o artificioso, a su otra posibilidad, es decir: "hecho con arte". Así, un artefacto será "un producto que surge de la inteligencia y de la sensibilidad que la actividad humana puede expresar" (p. 16). Sin embargo, para que esto sea posible, tal vez se deba atender a CO\&AC (2006) cuando insiste en que "la elegancia de la ingeniería óptima debe ser reemplazada por la ornamentación necesaria de la verdadera función" (p. 5), dirigida hacia "los deseos y los sueños" (p. 5).

\section{Conclusiones}

La ciencia-ficción se ha hecho cargo de sostener una mirada crítica sobre los cambios que derivan de los avances tecnológicos. El Steampunk, con su particular abordaje del pasado, no descuida este cometido que hereda de su género padre. Jeter parecía saberlo muy bien cuando, al pensar en el nombre de lo que vio como un flamante género literario, vinculó un tipo de tecnología (steam) con la palabra "Punk". Sin embargo, es de considerar que todo acto inaugural desconoce las proyecciones de aquello que de algún modo habilita. Es así que una prolifera subcultura nace de las imágenes que muestran un Londres victoriano sembrado de aparatos que, con el ropaje técnico de su época, realizan prodigios del futuro. De a poco, todas las áreas de la producción visual comienzan a verse impregnadas de esa estética retrofuturista. Perpleja y seducida por la visión de un tiempo falso, la mayoría de las personas que ingresa al Steampunk lo hace persiguiendo una fantasía que le permite huir del presente.

Pero esto no es Steampunk, aseguran los analistas más acérrimos. Y no basta con armarse a consciencia de un ánimo cuestionador. Porque la idea de que esta subcultura nace en realidad de una insatisfacción con los productos masivos es sólo el principio. Hay que convertirse en un hacedor de artefactos. De aquí se sigue que el Steampunk está hecho en verdad por los makers. Como se vio, éstos últimos rehacen objetos de uso cotidiano, aunque la mayor expresión crítica es alcanzada por las intervenciones que se realizan sobre dispositivos actuales de tecnología informática. Es que el diseño de estos productos, en la versión lanzada por el mercado, es tachado de impersonal, desalmado y desechable.

Se trata de objetos bruñidos que, sin hendiduras ni partes, se desmaterializan para ser únicamente sus prestaciones. Son el espacio del pleno consumo. El tacto, inconmovible ante un deslizamiento sin obstáculos, acepta lo que la vista no puede controvertir. Por otro lado, estos aparatos pasan por la vida de sus usuarios, advertidos sólo (o tal vez) en la novedad de su adquisición. Luego se retiran a una existencia muda que aguarda la pronta llegada de un sucesor.

Quedó probada, en este sentido, la importancia que le atribuye el Steampunk a que los objetos puedan recobrar tres elementos que se hallan interrelacionados: entidad física, personalización y durabilidad. De esta forma, la recuperación material incrementa la experiencia sensitiva; la intervención personal deviene en una apropiación; y postergar la 
caducidad logra un mayor tiempo de permanencia del objeto en la vida del usuario. Tales características, más la evocación de un pasado, añaden a los dispositivos un aspecto emocional que modifica la relación que se tiene con ellos.

Es en el siglo XIX entonces, donde se ve dada una tecnología configurada según un tipo análogo al recién planteado. Pero cabe recordar que la idea de "volver" a ese tiempo no queda circunscripta a estas cuestiones. Tampoco se trata del acontecimiento lúdico que podría significar vivir, mediante el uso de artefactos steampunk, en aquel porvenir imaginado por las mentes de Verne y Wells. La cita a un momento histórico que, como se ha dicho en más de una ocasión, no es aleatoria para el Steampunk, implica la intención de retomar, de alguna manera, el positivismo científico victoriano que prometió al hombre la superación de sus límites en una existencia venturosa.

Con todo, ¿se podría decir que, rechazando una fantasía ingenua, los makers han caído indefectiblemente en otra? Porque si bien contribuye a un cambio en la relación con la tecnología un viraje de su dimensión estética, ¿podrá alcanzar este modo alguna prosperidad si no se modifica esencialmente el tipo de tecnología y su veloz producción en serie? Además, ante la obvia imposibilidad de expandir suficientemente sus prácticas, el Steampunk (el que se declara como verdadero) queda reducido a la actividad de un pequeño grupo. Éste continuará con su trabajo seguramente, si es que no cede en algún momento a la idea de que ese mecanismo de constante renovación es un monstruo verniano de inmensos tentáculos, difícil de abatir.

Curiosos artefactos quedarán entonces como un ensayo de frenar el tiempo, de detener la aceleración en la que el contexto objetual, como se ve el paisaje en un tren que marcha a toda velocidad, corre fantasmal hacia un atrás irrecuperable. Incluso William Morris, con quien VanderMeer (2011) compara a los makers, luego de pedir socorro al pasado y en el umbral de un posible triunfo revolucionario, "retrocedió y se apartó gradualmente, de vuelta hacia un mundo de poesía y de belleza” (Pevsner, 2000, p. 23).

\section{Notas}

1. Este grupo, decidido a no revelar las identidades de sus integrantes, dice estar compuesto por Professor Calamity (su fundador), Dr. Virgil Disgr4ce, Rastrix Oxide y NealLißt. Ellos proclaman haberse reunido para sublevar a los steampunks en contra de sus opresores tecnológicos (Kuemmerlein, 2007).

2. Del inglés dystopia, lo que podría traducirse como antiutopía o utopía negativa. La distopía manifiesta el temor frente a la idea de una utopía realizable, pero no en términos de una sociedad ideal, sino como un orden perjudicial para el ser humano (La llamada es nuestra). 


\section{Bibliografía}

Bookchin, M. (1999). La Ecología de la Libertad. La Emergencia y la Disolución de las Jerarquías. Madrid: Nossa y Jara Editores.

Calamity, P. (2007). Entrevista por Marian Kuemmerlein, "Calamity and Catastrophe. Steampunks and the War Against Electricity", The L Magazine. Vol. 5, No. 14. [Texto online consultado en julio de 2012.] www.thelmagazine.com/newyork/calamity-andcatastrophe/Content?oid $=1138458$.

Catastrophone Orchestra and Arts Collective (2006). "What then is Stampunk?" The SteamPunk Magazine, № 1.

Clute, J. y Grant, J. (1999). “Steampunk”, The Encyclopedia of Fantasy, Contributing editors: Mike Ashley, Roz Kaveney, David Langford, Ron Tiner (Rev. edición), New York: St. Martin's Griffin.

Gross, C. (2006). "Varieties of Steampunk Experience", SteamPunk Magazine, No 1.

Han, B-C. (2005). La Salvación de lo Bello. Buenos Aires: Herder.

Kuemmerlein, M. (2007). "Calamity and Catastrophe. Steampunks and the War Against Electricity”, The L Magazine. Vol. 5, No. 14. [Texto online consultado en julio de 2012]. www.thelmagazine.com/newyork/calamity-and- catastrophe/Content?oid=1138458.

Manzini, E. (1996). Artefactos. Hacia una nueva ecología del ambiente artificial. Madrid: Celeste Ediciones.

Millás, J. J. (1982). Prólogo a la obra de Wells H. G., La máquina del tiempo. Madrid: Hyspamerica / Ediciones Generales Anaya.

Mumford, L. (2006). Técnica y Civilización. Madrid: Alianza. Título original: Technics and Civilization, 1934.

Mumford, L. (2010). El Mito de la Máquina. Técnica y Evolución Humana, Logroño: Editorial Pepitas de Calabaza. Título original: The Myth of the Machine. Technics and Human Development, 1967.

Nagy, R. (2011). “Sweat, Steam, and Mods: Steampunk Makers”, The Steampunk Bible. An illustrated guide to the world of imaginary airships, corsets and goggles, mad scientists, and strange literature. New York: Abrams Image.

Nagy, R. Datamancer. Modern Heirlooms with Classic Style. [Texto online consultado en julio de 2012] www.datamancer.net.

Norman, D. (2005). El diseño emocional. Barcelona: Paidós.

Onion, R. (1998). "Reclaiming the Machine: An Introductory Look at Steampunk in Everyday Practice”. Revista digital Neo-Victorian Studies No 1.

Pauwels, L. y Bergier, J. (1975). El retorno de los brujos. Barcelona: Plaza \& Janés. Título original: Le Matin des Magiciens, 1960.

Pevsner, N. (2000). Pioneros del Diseño Moderno. Buenos Aires, Ediciones Infinito.

Slatt, J. V. (2009). Entrevista por Inés Muñoz Martínez-Mora, "Punk del siglo XIX”, El País. com. [Texto online consultado en julio de 2012].

Slatt, J. V. (2011). "A Steampunk Manifesto", The Steampunk Bible. An illustrated guide to the world of imaginary airships, corsets and goggles, mad scientists, and strange literature. New York: Abrams Image. 
Slatt, J. V. Steampunk Workshop [Texto online consultado en julio de 2012]. www.steampunkworkshop.com

Sterling, B. (2011). “The User's Guide to Steampunk”, The Steampunk Bible. An illustrated guide to the world of imaginary airships, corsets and goggles, mad scientists, and strange literature. New York: Abrams Image.

Vandermeer, J. (2011). The Steampunk Bible. An illustrated guide to the world of imaginary airships, corsets and goggles, mad scientists, and strange literature. New York: Abrams Image.

Wetherell, T. [Texto online consultado en julio de 2012]. www.platypusart.com/wetherell/

\begin{abstract}
In this paper we address the genealogy of this concept that seeks to contextualize the works that take place in the future imagined by the science fiction writers Jules Verne and H. G. Wells, in the late nineteenth century. Turned into a subculture in the 1990s, Steampunk recovers for its aesthetics elements of the Victorian machine. This procedure can be observed today, and increasingly so, in the different fields of visual production. The analysis aims to analyse the ways in which some of the objects produced by this subculture acquire a critical dimension.
\end{abstract}

Keywords: Steampunk - Science Fiction - Criticism.

Resumo: Neste artigo abordamos a genealogia deste conceito que procura contextualizar as obras que ocorrem no futuro imaginado pelos escritores de ficção científica Jules Verne e H. G. Wells, no final do século XIX. Transformada em uma subcultura nos anos 90, a Steampunk recupera por seus elementos estéticos da máquina vitoriana. Este procedimento pode ser observado hoje, e cada vez mais, nos diferentes campos da produção visual. A análise visa analisar as formas pelas quais alguns dos objetos produzidos por esta subcultura adquirem uma dimensão crítica.

Palavras chave: Steampunk - Fiç̧ão Científica - Crítica.

[Las traducciones de los abstracts fueron supervisadas por el autor de cada artículo] 